\title{
Powder diffraction in structural characterization of dienediaminoketones of the indolin-3-one series
}

\author{
VLADIMIR V CHERNYSHEV ${ }^{1,2, *}$ and NATALIA S MONAKHOVA ${ }^{3}$ \\ ${ }^{1}$ Department of Chemistry, M.V. Lomonosov Moscow State University, 119991 Moscow, \\ Russian Federation \\ ${ }^{2}$ A.N. Frumkin Institute of Physical Chemistry and Electrochemistry, Leninsky prospect 31, \\ 119991 Moscow GSP-1, Russian Federation \\ ${ }^{3}$ Department of Medicinal Chemistry, State Scientific Center for Antibiotics, \\ Nagatinskaya Str. 3a, 117105 Moscow, Russian Federation \\ e-mail: vladimir@struct.chem.msu.ru
}

\begin{abstract}
Crystal structures of five derivatives of dienediaminoketones - 3-amino-3-(dimethylamino)2-[(3-oxo-1,3-dihydro-2H-indol-2-ylidene)methyl]acrylonitrile (1); 3-amino-2-[(3-oxo-1,3-dihydro-2Hindol-2-ylidene)methyl]-3-pyperidin-1-ylacrylonitrile $\quad(2) ; \quad 3$-amino-3-morpholin-4-yl-2-[(3-oxo-1,3dihydro-2H-indol-2-ylidene)methyl]acrylonitrile (3); 3-amino-3-[(4-methoxyphenyl)amino]-2-[(3-oxo-1,3dihydro-2H-indol-2-ylidene)methyl]acrylonitrile (4) and 3-amino-3-(benzylamino)-2-[(3-oxo-1,3dihydro-2H-indol-2-ylidene)methyl]acrylonitrile (5) - were determined from powder patterns measured with the laboratory powder diffractometer. The single crystal structure of the hydrate of ethanol solvate of $3-3 \cdot 0 \cdot 33 \mathrm{C}_{2} \mathrm{H}_{6} \mathrm{O} \cdot 0 \cdot 33 \mathrm{H}_{2} \mathrm{O}(\mathbf{3 a})-$ is also presented. The hydrogen-bonding patterns of all compounds are discussed.
\end{abstract}

Keywords. Structure determination from powder data; Rietveld refinement; dienediaminoketone; hydrogen bonding.

\section{Introduction}

X-Ray powder diffraction (XRPD) is now one of the most widely used techniques available to materials scientists for studying the structure and microstructure of crystalline solids. XRPD is a routine tool for qualitative and quantitative phase analysis, and an important method for material characterization, probing strain, stress, texture, defects and stacking faults in a large variety of structures. In the last decade, a major advance has occurred in the determination of crystal structure $a b$ initio from powder diffraction data, ${ }^{1-5}$ in cases where suitable single crystals are not available. Plenty of computer programs have been developed for crystal structure determination and refinement with XRPD dataDASH ${ }^{6}$ ESPOIR, ${ }^{7}$ EXPO, ${ }^{8}$ FOX, ${ }^{9}$ FullProf, ${ }^{10}$ GSAS, $^{11}$ MRIA $^{12}$ and TOPAS ${ }^{13}$ are among many others. Numerous research groups working in universities and industrial laboratories actively use various methods for the structure determination by XRPD and obtain reliable three-dimensional struc-

*For correspondence tures (recent examples in $^{14-19}$ ). It is worthy to note that the majority of new crystal structures determined by XRPD were solved from powder diffraction data measured with laboratory devices. It means that any group having in-house well-aligned powder diffractometer can join to aforementioned powder community probing three-dimensional structures of new materials. To illustrate this statement, we present here the results of structural investigation of several compounds from the family of dienediaminoketones.

It is known that enaminoketones smoothly react with compounds containing active methylene groups to form functionally substituted olefins. ${ }^{20,21}$ However, when Ryabova and co-workers attempted to obtain 2-( $\beta, \beta$-dicyanovinyl)-3-hydroxyindole by condensation of 2-dimethylaminomethylene- and 2piperidinomethyleneindolin-3-3-ones with malononitrile they discovered new direction of the reaction with the yield of 2-(2-cyano-3-amino-3-dialkylaminoprop-2-enylidene)indolin-3-ones. ${ }^{22} \quad$ Among new derivatives of dienediamines of indolin-3-one, low-toxicity compounds possessing antihypertensive activity for both intravenous and oral introduction 
were found. ${ }^{22}$ To investigate stability of these compounds in the solid state under ambient conditions and to check the possibility of their polymorphic transformations during the storage, we tried to find crystal structures of their anhydrous forms in free base state. Five compounds were tested for crystallization, namely:
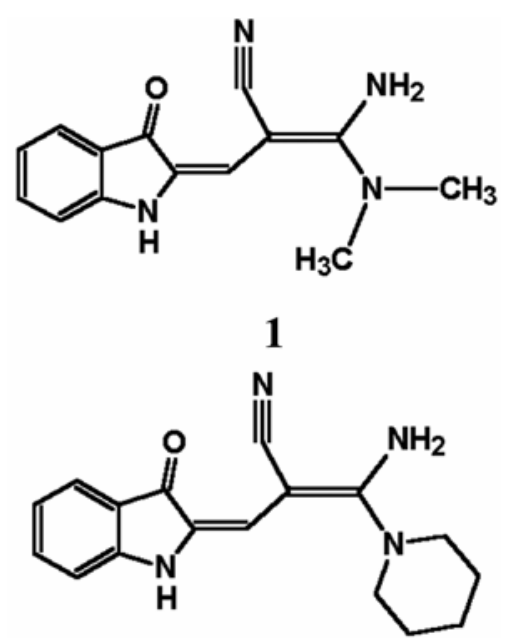

2

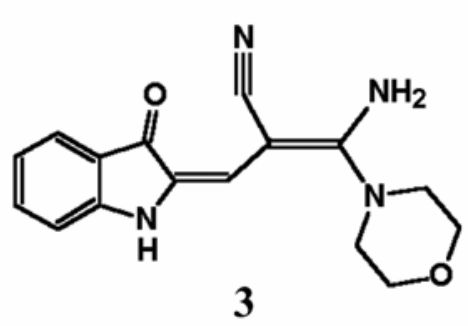

3

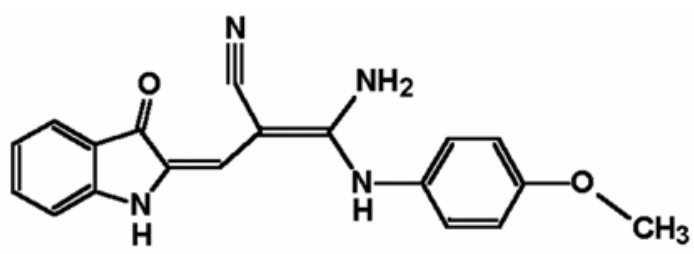

4

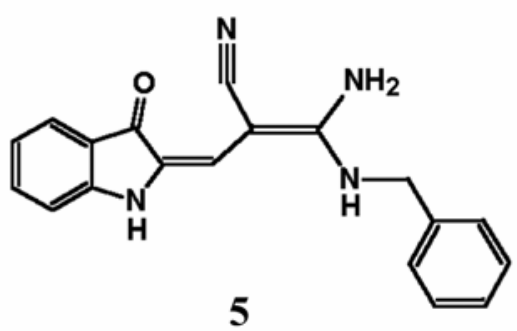

3-Amino-3-(dimethylamino)-2-[(3-oxo-1,3-dihydro2H-indol-2-ylidene)methyl]acrylonitrile (1); 3Amino-2-[(3-oxo-1,3-dihydro-2H-indol-2-ylidene) methyl]-3-pyperidin-1-ylacrylonitrile (2); 3-Amino-
3-morpholin-4-yl-2-[(3-oxo-1,3-dihydro-2H-indol2-ylidene)methyl]acrylonitrile (3); 3-Amino-3-[(4methoxyphenyl)amino]-2-[(3-oxo-1,3-dihydro-2Hindol-2-ylidene)methyl]acrylonitrile (4); 3-Amino3-(benzylamino)-2-[(3-oxo-1,3-dihydro-2H-indol-2ylidene)methyl]acrylonitrile (5).

None of them produced single-crystals of X-ray quality, instead they produced polycrystalline powders of different quality. Their powder patterns were measured with a laboratory diffractometer and used in successful crystal structure determinations. Here we present these crystal structures along with the details of indexing of their powder patterns, solving and subsequent refinement, and discuss observed hydrogen bonding patterns. The hydrate of ethanol solvate of $3-3 \cdot 0 \cdot 33 \mathrm{C}_{2} \mathrm{H}_{6} \mathrm{O} \cdot 0 \cdot 33 \mathrm{H}_{2} \mathrm{O}(\mathbf{3 a})$ - has been unintentionally obtained in multiple attempts to synthesize unsolvated form of $\mathbf{3}$. Its crystal structure solved from single-crystal data is also presented here.

\section{Experimental}

\subsection{Synthesis}

Compounds 1-5 were synthesized following the reported method. ${ }^{22} \mathbf{1}, 2$ and 4 were recrystallized from dimethylformamide:water $(1: 1)$ solution, $\mathbf{3}$ - from ethanol:water $(1: 1)$ solution, and $\mathbf{5}$ - from dimethylformamide. All solids were dried in vacuo for $6 \mathrm{~h}$. Single crystals of $\mathbf{3 a}$ of poor quality were selected from the crude product of recrystallized compound 3 before drying in vacuo.

\subsection{DFT calculations}

Density functional theory (DFT) calculations for the molecules of 1-5 in vacuo were performed using the PRIRODA program. ${ }^{23,24}$ For representation of the Kohn-Sham one-electron wavefunctions, sets of contracted Gaussian-type functions were used; the contracted patterns were $(311 / 1)$ for $\mathrm{H}$ and $(611111 / 411 / 11)$ for $\mathrm{C}, \mathrm{N}$ and $\mathrm{O}$. The geometry optimization was performed using the quasi-Newton method to the final gradient of $10^{-5}$ Hartree $\AA^{-1}$.

\subsection{Crystal structure determination}

2.3a Data collection and indexing: X-ray powder patterns were measured in transmission mode with a G670 Guinier camera diffractometer $\left(\mathrm{CuK}_{\alpha_{1}}\right.$ radia- 
Table 1. Crystal data for $\mathbf{1 - 5}$.

\begin{tabular}{|c|c|c|c|c|c|}
\hline & 1 & 2 & 3 & 4 & 5 \\
\hline Empirical formula & $\mathrm{C}_{14} \mathrm{H}_{14} \mathrm{~N}_{4} \mathrm{O}$ & $\mathrm{C}_{17} \mathrm{H}_{18} \mathrm{~N}_{4} \mathrm{O}$ & $\mathrm{C}_{16} \mathrm{H}_{16} \mathrm{~N}_{4} \mathrm{O}_{2}$ & $\mathrm{C}_{19} \mathrm{H}_{16} \mathrm{~N}_{4} \mathrm{O}_{2}$ & $\mathrm{C}_{19} \mathrm{H}_{16} \mathrm{~N}_{4} \mathrm{O}$ \\
\hline$f w$ & $254 \cdot 29$ & $294 \cdot 35$ & $296 \cdot 33$ & $332 \cdot 36$ & $316 \cdot 36$ \\
\hline $\begin{array}{l}\text { Particle morphology, } \\
\text { colour }\end{array}$ & $\begin{array}{l}\text { Plate, dark } \\
\text { brown }\end{array}$ & $\begin{array}{l}\text { No specific } \\
\text { habit, brown }\end{array}$ & $\begin{array}{l}\text { No specific } \\
\text { habit, dark red }\end{array}$ & $\begin{array}{l}\text { No specific } \\
\text { habit, brown }\end{array}$ & $\begin{array}{l}\text { No specific } \\
\text { habit, dark red }\end{array}$ \\
\hline Crystal system & Monoclinic & Monoclinic & Monoclinic & Monoclinic & Monoclinic \\
\hline Space group & $P 2_{1} / c$ & $P 2_{1} / c$ & $C 2 / c$ & $P 2_{1} / c$ & $P 2_{1} / c$ \\
\hline \multicolumn{6}{|l|}{ Unit cell dimensions } \\
\hline$a(\AA)$ & $13 \cdot 862(4)$ & $15 \cdot 467(2)$ & $16 \cdot 9631(15)$ & $16 \cdot 843(5)$ & $13 \cdot 8622(18)$ \\
\hline$b(\AA)$ & $7 \cdot 575(3)$ & $11 \cdot 8497(13)$ & $20 \cdot 924(2)$ & $17 \cdot 901(5)$ & $4 \cdot 9521(7)$ \\
\hline$c(\AA)$ & $12 \cdot 364(4)$ & $9 \cdot 9206(9)$ & $9 \cdot 5676(11)$ & $10 \cdot 968(2)$ & $23 \cdot 914(2)$ \\
\hline$\alpha\left(^{\circ}\right)$ & 90 & 90 & 90 & 90 & 90 \\
\hline$\beta\left(^{\circ}\right)$ & $102 \cdot 99(2)$ & $122 \cdot 691(17)$ & $117 \cdot 852(17)$ & $94 \cdot 369(19)$ & $100 \cdot 136(16)$ \\
\hline$\gamma\left({ }^{\circ}\right)$ & 90 & 90 & 90 & 90 & 90 \\
\hline Volume $\left(\AA^{3}\right)$ & $1265 \cdot 1(7)$ & $1530 \cdot 2(3)$ & $3002 \cdot 5(5)$ & $3297 \cdot 3(15)$ & $1616 \cdot 0(3)$ \\
\hline$M_{20}{ }^{\mathrm{a}}$ & 44 & 70 & 28 & 29 & 36 \\
\hline$F_{30}$ & $59(0.009,57)$ & $100(0 \cdot 006,48)$ & $25(0.008,142)$ & $47(0 \cdot 010,46)$ & $69(0 \cdot 010,46)$ \\
\hline$Z^{30}$ & 4 & 4 & 8 & 8 & 4 \\
\hline$\mu\left(\mathrm{mm}^{-1}\right)$ & 0.716 & 0.663 & 0.732 & 0.732 & 0.672 \\
\hline $\begin{array}{l}2 \theta_{\min }-2 \theta_{\max } \\
\text { increment }\left(^{\circ}\right)\end{array}$ & $\begin{array}{l}4 \cdot 00-100 \cdot 50 \\
0 \cdot 01\end{array}$ & $\begin{array}{l}4 \cdot 00-90 \cdot 00 \\
0 \cdot 01\end{array}$ & $\begin{array}{l}4 \cdot 00-80 \cdot 00 \\
0 \cdot 01\end{array}$ & $\begin{array}{l}3 \cdot 00-100 \cdot 00 \\
0 \cdot 01\end{array}$ & $\begin{array}{l}4 \cdot 00-90 \cdot 00 \\
0 \cdot 01\end{array}$ \\
\hline No. params/restraints & $112 / 64$ & $124 / 82$ & $101 / 74$ & $236 / 193$ & $132 / 87$ \\
\hline \multirow{2}{*}{$R_{\mathrm{p}} / R_{\mathrm{wp}} / R_{\exp }^{\mathrm{c}}$} & $0 \cdot 018 / 0 \cdot 024 /$ & $0 \cdot 016 / 0 \cdot 022 /$ & $0 \cdot 013 / 0 \cdot 017 /$ & $0 \cdot 017 / 0 \cdot 023 /$ & $0 \cdot 018 / 0 \cdot 025 /$ \\
\hline & $0 \cdot 012$ & $0 \cdot 011$ & $0 \cdot 012$ & $0 \cdot 011$ & $0 \cdot 011$ \\
\hline GOF & 1.957 & $2 \cdot 079$ & $1 \cdot 476$ & $2 \cdot 180$ & $2 \cdot 208$ \\
\hline
\end{tabular}

${ }^{\mathrm{a}} M_{20}$ is defined according to. ${ }^{34 \mathrm{~b}} F_{30}$ is defined according to. ${ }^{35 \mathrm{c}} R_{p}, R_{w p}$ and $R_{\text {exp }}$ are defined according to ${ }^{36}$

tion, $\lambda=1.54059 \AA)$ at ambient conditions ( $\mathrm{T}=295(2)$ K) for $8 \mathrm{~h}$ each. To reduce preferred orientation effects, each powder sample was prepared as a thin layer sprinkled on mylar foil using a little sieve. In addition to specimen oscillation, it was manually rotated on 60 centidegrees each $30 \mathrm{~min}$ of measurements.

The detection of peaks and the location of their positions, which may not coincide with their maxima, was carried out with the program MRIA, first by automatic peak search option and then by careful manual inspection. The monoclinic unit-cell dimensions of 1-5 were determined using the positions of 30-50 peaks and three indexing programs: TREOR90, ${ }^{25}$ ITO $^{26}$ and AUTOX. ${ }^{27,28}$ Space groups for all compounds were assigned on the bases of systematic extinctions. The unit-cell parameters and space groups were further tested using Pawley's fit $^{29}$ and confirmed by crystal structure solution. The crystallographic data for 1-5 are given in table 1 .

For solvate 3a, intensity data set was collected at room temperature using an Enraf-Nonius CAD4 diffractometer $(\mathrm{CuK} \alpha$ radiation, $\lambda=1.54184 \AA)$ equipped with a graphite monochromator. Its crystallographic data are given in table 2. In view of poor quality of the crystal, the intensities were collected up to $\theta=50^{\circ}$ only.
Table 2. Crystal data for 3a (single-crystal sample).

\begin{tabular}{ll}
\hline & \multicolumn{1}{c}{$3 \mathbf{a}$} \\
\hline Empirical formula & $\mathrm{C}_{16} \mathrm{H}_{16} \mathrm{~N}_{4} \mathrm{O}_{2} \cdot 0 \cdot 33 \mathrm{C}_{2} \mathrm{H}_{6} \mathrm{O} \cdot 0 \cdot 33 \mathrm{H}_{2} \mathrm{O}$ \\
Temp (K) & $295(2)$ \\
$f w$ & $317 \cdot 69$ \\
Crystal size $\left(\mathrm{mm}^{3}\right)$ & $0 \cdot 20 \times 0 \cdot 16 \times 0 \cdot 10$ \\
Crystal form, colour & Prism, dark red \\
Crystal system & Triclinic \\
Space group & $P-1$ \\
Unit cell dimensions & \\
$\quad a(\AA)$ & $12 \cdot 259(7)$ \\
$b(\AA)$ & $14 \cdot 145(4)$ \\
$\quad c(\AA)$ & $14 \cdot 326(4)$ \\
$\quad \alpha\left({ }^{\circ}\right)$ & $99 \cdot 46(2)$ \\
$\quad \beta\left(^{\circ}\right)$ & $101 \cdot 61(4)$ \\
$\gamma\left({ }^{\circ}\right)$ & $92 \cdot 28(3)$ \\
Volume $\left(\AA^{3}\right)$ & $2393 \cdot 3(17)$ \\
$Z$ & 6 \\
$\left.\mu(m)^{-1}\right)$ & $1 \cdot 323$ \\
$\quad$ No. reflns collected/ & $5312 / 4907[R($ int $)=0 \cdot 057]$ \\
$\quad$ independent & \\
No. params/restraints & $639 / 3$ \\
GOF & $1 \cdot 020$ \\
Final $R$ indices & $R(F)=0 \cdot 0520(3012$ reflns with \\
& \multicolumn{1}{c}{$I>2 \sigma(I)), w R\left(F^{2}\right)=0 \cdot 1552$} \\
\hline
\end{tabular}

2.3b Structure solution: The crystal structures of 1-5 have been solved by simulated annealing tech- 
nique. ${ }^{30}$ In the absence of crystal structures with close molecular models in Cambridge Structural Database (CSD, Version 5.31; 2010 Release) ${ }^{31}$ the molecular geometries of 1-5 were optimized by DFT calculations with a program PRIRODA. ${ }^{23,24}$ All molecules are relatively rigid and main features of their molecular conformations are predictable, so no more than 3 torsional degrees of freedom were varied for each independent molecule in simulated annealing runs in addition to 3 translational and 3 orientational degrees of freedom. For compound 4, which contains two independent molecules in the asymmetric unit, the total number of varied degrees of freedom was 18 - a routine case for modern software.

2.3c Rietveld refinement: The DFT optimized molecular geometries were used as templates in the final bond-restrained Rietveld refinements. The patterns were fitted with the program MRIA using a split-type pseudo-Voigt peak-profile function. ${ }^{32}$ For all compounds, excluding 3, all non-H atoms were isotropically refined. For 3, in view of poor pattern, one common $U_{\text {iso }}$ parameter for all non-H atoms was refined. Restraints were applied to the intramolecular bond lengths and contacts $(<2.8 \AA)$, the strength of the restraints was a function of interatomic separation and, for intramolecular bond lengths, corresponded to an r.m.s. deviation of $0.03 \AA$. Additional restraints were applied to the planarity of the ring systems with the attached atoms, with the maximal allowed deviation from the mean plane of $0.05 \AA$. The $\mathrm{H}$ atoms were placed in geometrically idealized positions (C-H 0.93-0.97 $\AA, \mathrm{N}-\mathrm{H} 0.86 \AA)$ and not refined. The diffraction profile after the final bondrestrained Rietveld refinement for $\mathbf{1}$ is shown in figure 1 , the diffraction profiles for the rest of the compounds can be found in supplementary data (figure S1).

2.3d Structure determination of solvate 3a: The structure was solved from single-crystal data with SHELXS $97^{33}$ and refined with SHELXL97. ${ }^{33}$ All hydrogen atoms were placed in idealized positions (O-H 0.82-0.85 $,, \mathrm{N}-\mathrm{H} 0.86 \AA, \mathrm{C}-\mathrm{H} 0.93-0.97 \AA)$, and refined as riding with $U_{\text {iso }}(\mathrm{H})=1.2-1.5 U_{e q}$ of the parent atom.

\section{Results and discussion}

We discuss first some aspects of crystal structure determinations of 1-5 from powder diffraction data.

\subsection{Indexing}

A rough estimation of success rate in crystal structure determination for organic and metal-organic compounds from powder diffraction data in case of correct indexing gives $99 \%$. Therefore, the indexing is becoming more and more important stage in the full structural characterization of powder substances. A successful and reliable indexing is based on a set of accurately determined peak positions. Our powder patterns measured with a G670 Guinier camera demonstrate strong asymmetry of low-angle peaks (see figure 2), which may cause some difference between the real peak position and its experimental maximum. These differences are small, usually no more than $0.07^{\circ}$, but they are important for the proper work of indexing program, which are sensible to deviations from the real peak positions exceeding $0.03^{\circ}$. In our case, use of split-type pseudo-Voigt function ${ }^{32}$ in analytical approximation of experimental peak (see figure 2) allowed us accurately determine its real position.

Molecules 1-5 contain no more than 30 non-H atoms, so we did not expected serious problems with indexing even for structures with two independent molecules in asymmetric unit as was the case of $\mathbf{4}$. Nevertheless, we have encountered a problem while indexing powder pattern of 3 . Initially, it was indexed in triclinic unit cell with $a, b, c, \alpha, \beta, \gamma$ equal to $9.36 \AA, 12.45 \AA, 7.01 \AA, 97.53^{\circ}, 110.04^{\circ}$ and $78.79^{\circ}$, respectively, with a volume of $751 \AA^{3}$. However, all attempts to solve crystal structure of $\mathbf{3}$

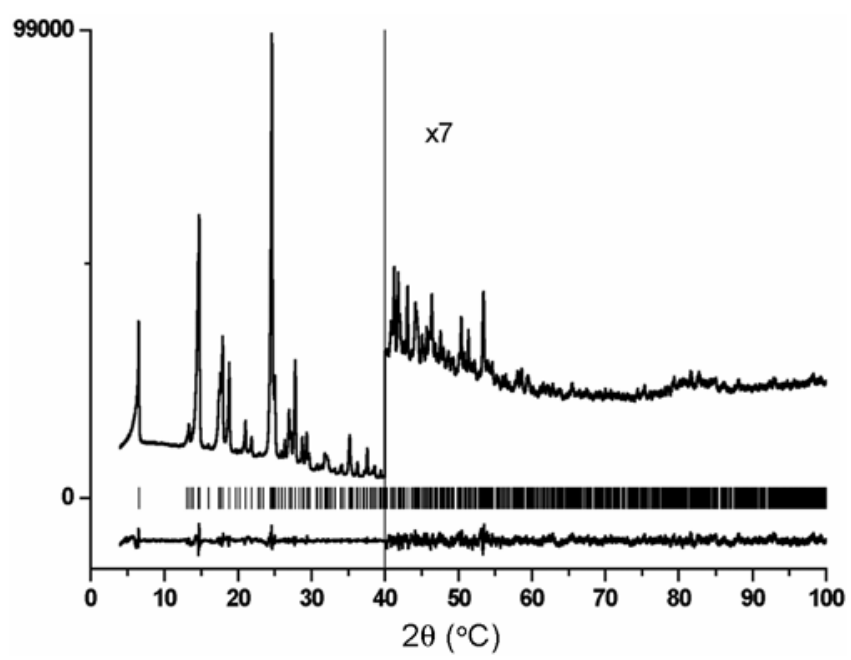

Figure 1. The Rietveld plot, showing the observed and difference profiles for $\mathbf{1}$. The reflection positions are shown as vertical bars above the difference profile. 
in this triclinic unit cell failed in both possible space groups $-P-1$ and $P 1$. Powder sample of $\mathbf{3}$ has been obtained after several unsuccessful attempts to crystallize 3 from various solvents, and it produced poor powder pattern with the broad peaks. Therefore, the peak positions were defined with the higher errors. Keeping the latter in mind, the Niggli matrix was carefully inspected with the higher feasible deviations for dependencies between their elements. A possible transformation to monoclinic $\mathrm{C}$-centered unit cell has been found and crystal structure $\mathbf{3}$ has been solved in $C 2 / c$ space group.

\subsection{Structure solution and refinement}

The molecular structures of 1-5 determined from powder data are shown on figures 3 and 4 . The molecular conformations of atomic fragments containing 17 atoms numbered from $1(\mathrm{~N} 1)$ to $17(\mathrm{~N} 17)$ are approximately the same in all compounds, and they correspond to those obtained in DFT optimizations. Thus, in the cases of new molecules which are absent in structural databases, their DFT optimized molecular geometries can be successfully used in direct space search while solving crystal structure from powder data. It is worthy to note, that we determined here the crystal structures of several close compounds thus validating each structure based on regularities observed in all structures. We used the same approach in structural characterization of nine new derivatives of $[1,4]$ diazepino[6,5b]indoles by powder diffraction. ${ }^{37}$

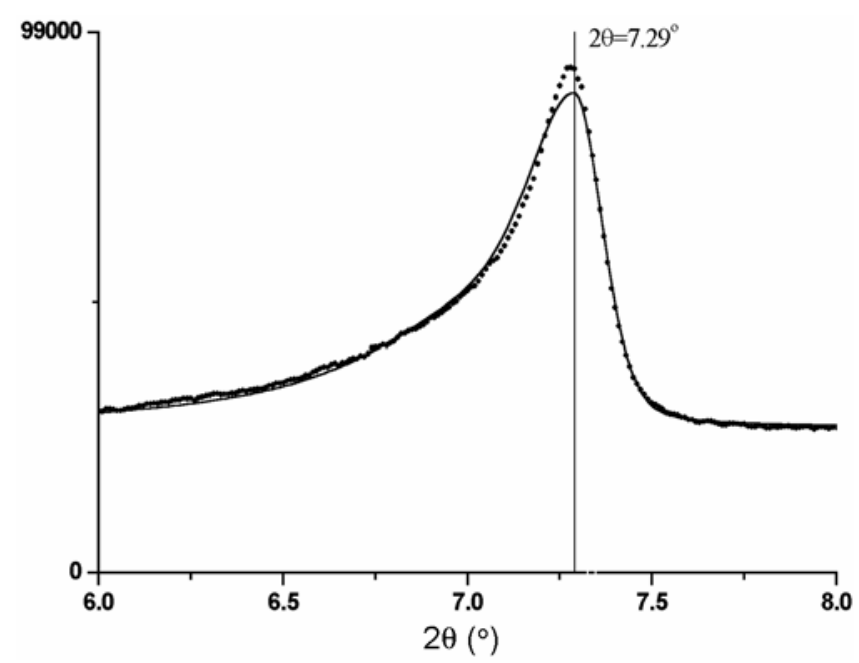

Figure 2. Experimental diffraction peak 110 (dots) with a calculated position $2 \theta_{110}$ of $7 \cdot 29^{\circ}$ analytically approximated with split-type pseudo-Voigt function (solid line).
The crystal structures 1-5 are of relatively poor quality, because their experimental data sets contained not so many reliable observations, i.e. wellresolved diffraction peaks. This required an exten-
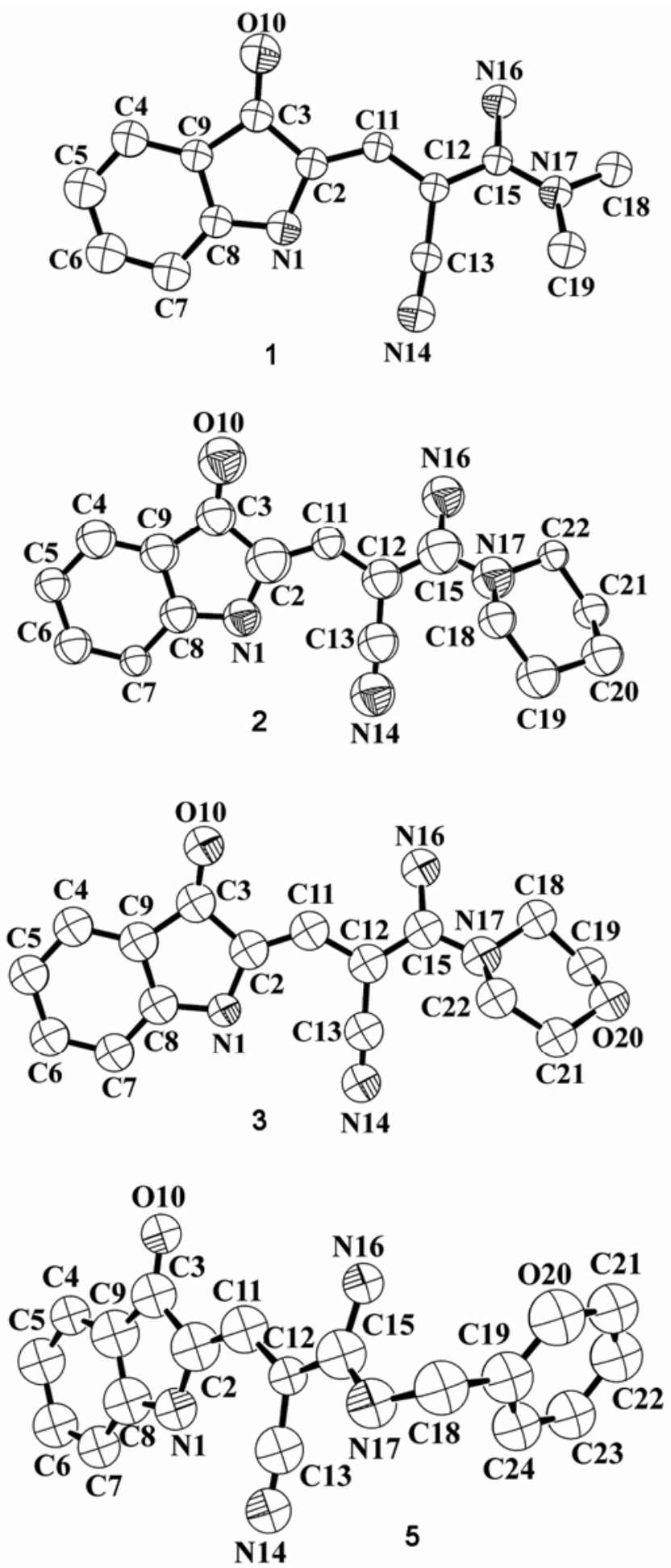

Figure 3. The molecular structures of 1-3 and 5 showing the atomic numbering and $50 \%$ probability displacement spheres. $\mathrm{H}$ atoms omitted for clarity. 
Table 3. Strong intermolecular hydrogen bonds $\left(\AA,{ }^{\circ}\right)$ in 1-5.

\begin{tabular}{|c|c|c|c|c|c|}
\hline Compound & $\mathrm{D}-\mathrm{H} \cdots \mathrm{A}$ & D-H & $\mathrm{H} \cdots \mathrm{A}$ & $\mathrm{D} \cdots \mathrm{A}$ & $\mathrm{D}-\mathrm{H} \cdots \mathrm{A}$ \\
\hline 1 & $\begin{array}{l}\text { N16-H16A } \cdots \mathrm{O} 10^{\mathrm{i}} \\
\text { N16-H16B } \cdots \mathrm{N}^{\text {ii }}{ }^{\mathrm{i}}\end{array}$ & $\begin{array}{l}0 \cdot 86 \\
0 \cdot 86\end{array}$ & $\begin{array}{l}2 \cdot 14 \\
2 \cdot 14\end{array}$ & $\begin{array}{l}2 \cdot 877(9) \\
2 \cdot 923(10)\end{array}$ & $\begin{array}{l}144 \\
151\end{array}$ \\
\hline 2 & $\begin{array}{l}\text { N16-H16A } \cdots O 10^{\text {iii }} \\
\text { N16-H16B } \cdots \mathrm{N}^{\text {iv }}\end{array}$ & $\begin{array}{l}0 \cdot 86 \\
0 \cdot 86\end{array}$ & $\begin{array}{l}1 \cdot 92 \\
2 \cdot 06\end{array}$ & $\begin{array}{l}2 \cdot 720(11) \\
2 \cdot 899(12)\end{array}$ & $\begin{array}{l}154 \\
167\end{array}$ \\
\hline 3 & $\begin{array}{l}\text { N16-H16A } \cdots O 10^{\mathrm{v}} \\
\mathrm{N} 16-\mathrm{H} 16 \mathrm{~B} \cdots \mathrm{O} 10^{\mathrm{vi}}\end{array}$ & $\begin{array}{l}0 \cdot 86 \\
0 \cdot 86\end{array}$ & $\begin{array}{l}2 \cdot 02 \\
2 \cdot 42\end{array}$ & $\begin{array}{l}2 \cdot 75(2) \\
2 \cdot 812(19)\end{array}$ & $\begin{array}{l}146 \\
109\end{array}$ \\
\hline 4 & $\begin{array}{l}\text { N16A-H16A } \cdots O 10 B \\
\text { N16A-H16B } \cdots \text { N14B } \\
\text { N16 } \\
\text { N16B-H16C } \cdots O 10 A \\
\text { N17A-H16D } \cdots \text { N14B } \\
\text { vii } \\
\text { N17B-H17B } \cdots \text { N14A } \\
\text { viii } \\
\text { ix }\end{array}$ & $\begin{array}{l}0 \cdot 86 \\
0 \cdot 86 \\
0 \cdot 86 \\
0 \cdot 86 \\
0 \cdot 86 \\
0 \cdot 86\end{array}$ & $\begin{array}{l}2 \cdot 20 \\
2 \cdot 20 \\
2 \cdot 18 \\
2 \cdot 38 \\
2 \cdot 19 \\
2 \cdot 09\end{array}$ & $\begin{array}{l}2 \cdot 872(10) \\
2 \cdot 966(11) \\
2 \cdot 865(10) \\
3 \cdot 105(12) \\
2 \cdot 969(12) \\
2 \cdot 840(10)\end{array}$ & $\begin{array}{l}135 \\
148 \\
136 \\
144 \\
152 \\
147\end{array}$ \\
\hline 5 & $\begin{array}{l}\text { N16-H16A } \cdots O 10^{\mathrm{x}} \\
\mathrm{N} 16-\mathrm{H} 16 \mathrm{~B} \cdots \mathrm{O} 10^{\mathrm{iii}} \\
\mathrm{N} 17-\mathrm{H} 17 \cdots \mathrm{N} 14^{\mathrm{xi}}\end{array}$ & $\begin{array}{l}0 \cdot 86 \\
0 \cdot 86 \\
0 \cdot 86\end{array}$ & $\begin{array}{l}2 \cdot 04 \\
2 \cdot 25 \\
2 \cdot 30\end{array}$ & $\begin{array}{l}2 \cdot 773(9) \\
2 \cdot 938(9) \\
2 \cdot 991(10)\end{array}$ & $\begin{array}{l}136 \\
137 \\
155\end{array}$ \\
\hline
\end{tabular}

Symmetry codes: (i) $1-x,-y, 1-z$; (ii) $x, 1 / 2-y, z-1 / 2$; (iii) $1-x, 1-y, 2-z$; (iv) $1+x, 1 / 2-y, 3 / 2+z$; (v) $1-x, 2-y, 1-z$; (vi) $x, 2-y, 1 / 2+z$; (vii) $x, 3 / 2-y$, $1 / 2+z$; (viii) $-x, 1-y,-z$; (ix) $x, 3 / 2-y, z-1 / 2$; (x) $1-x, 1-y, 2-z$; (xi) $-x, 1 / 2+y, 3 / 2-z$

Table 4. Strong intermolecular hydrogen bonds $\left(\AA,{ }^{\circ}\right)$ in 3a.

\begin{tabular}{|c|c|c|c|c|}
\hline $\mathrm{D}-\mathrm{H} \cdots \mathrm{A}$ & $\mathrm{D}-\mathrm{H}$ & $\mathrm{H} \cdots \mathrm{A}$ & $\mathrm{D} \cdots \mathrm{A}$ & $\mathrm{D}-\mathrm{H} \cdots \mathrm{A}$ \\
\hline N16A-H16A $\cdots O$ O10A ${ }^{i}$ & 0.86 & $2 \cdot 20$ & $2 \cdot 872(10)$ & 135 \\
\hline N16A-H16B $\cdots$ N14B ${ }^{\mathrm{ii}}$ & $0 \cdot 86$ & $2 \cdot 20$ & $2 \cdot 966(11)$ & 148 \\
\hline N16B-H16C…O2 & $0 \cdot 86$ & $2 \cdot 18$ & $2 \cdot 865(10)$ & 136 \\
\hline N16B-H16D $\cdots$ N14A & $0 \cdot 86$ & $2 \cdot 38$ & $3 \cdot 105(12)$ & 144 \\
\hline $\mathrm{N} 16 \mathrm{C}-\mathrm{H} 16 \mathrm{E} \cdots \mathrm{O} 10 \mathrm{C}^{\mathrm{iii}}$ & 0.86 & $2 \cdot 19$ & $2 \cdot 969(12)$ & 152 \\
\hline $\mathrm{N} 16 \mathrm{C}-\mathrm{H} 16 \mathrm{~F} \cdots \mathrm{O} 10 \mathrm{~B}^{\mathrm{iii}}$ & $0 \cdot 86$ & 2.09 & $2 \cdot 840(10)$ & 147 \\
\hline $\mathrm{O} 1-\mathrm{H} 1 \cdots \mathrm{O} 20 \mathrm{~B}^{\mathrm{iv}}$ & $0 \cdot 86$ & $2 \cdot 02$ & $2 \cdot 758(6)$ & 149 \\
\hline $\mathrm{O} 2-\mathrm{H} 2 \mathrm{C} \cdots \mathrm{O} 1$ & $0 \cdot 85(3)$ & $2 \cdot 03(5)$ & $2 \cdot 822(6)$ & 155 \\
\hline $\mathrm{O} 2-\mathrm{H} 2 \mathrm{D} \cdots \mathrm{O} 10 \mathrm{C}$ & $0 \cdot 85(3)$ & $1 \cdot 99(5)$ & $2 \cdot 809(5)$ & 160 \\
\hline
\end{tabular}

Symmetry codes: (i) $-x,-y, 2-z$; (ii) $x-1, y, z$; (iii) $1-x, 1-y, 2-z$; (iv) $1-x,-y, 1-z$

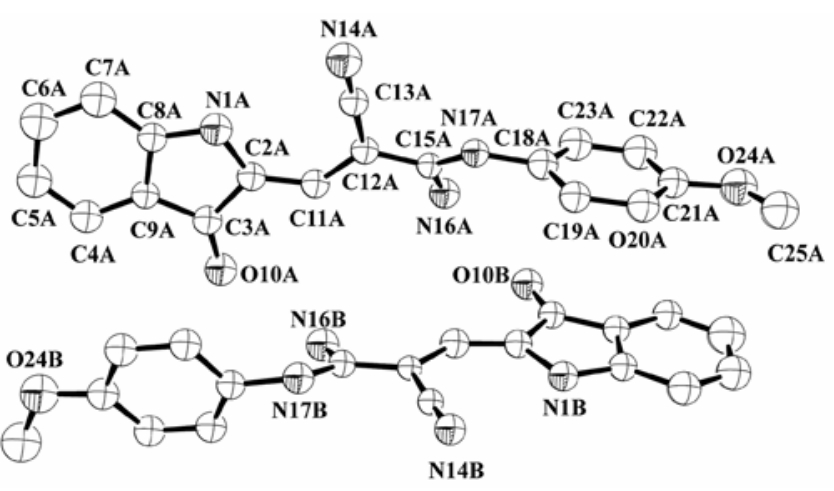

Figure 4. Two independent molecules - A and B, respectively - in asymmetric unit of $\mathbf{4}$ showing the atomic numbering and 50\% probability displacement spheres. Atomic numbering in molecule B corresponds to that in molecule A. H atoms omitted for clarity. sive use in the refinement of a number of strong restraints comparable with the number of variables (see table 1). As a result, the geometrical parameters for these compounds will not be discussed, because all bond lengths and angles correspond well to those obtained in DFT optimizations. Actually, in the refinement with the used strong restraints, the only variables were torsion angles. At the same time, the quality of all powder patterns, except 3, was good enough to allow the refinement of independent isotropic parameters $U_{\text {iso }}$ for all non-H atoms.

\subsection{Hydrogen-bonding patterns}

Despite the aforementioned crystallographic shortcomings, which do not allow us to discuss intra- 
molecular geometrical parameters in $\mathbf{1 - 5}$, the features of the crystal packing and hydrogen-bonding pattern are clear and unambiguous. Hydrogen bonds play an important role in formation of drug-protein complexes. ${ }^{38,39}$ so understanding the principles of their formation is vital in accelerating of computeraided drug-design. There is one more problem inherent with powder pharmaceutical substances which can be resolved with the help of known hydrogen-bonding pattern. This problem concerns the solubility and bioavailability of the substance after penetration into the living subject. Indeed, any drug molecule has one or more active centers - donors and/or acceptors of hydrogen bonds. Being stored in a solid state it can be crystallized in various polymorphic forms. It is important to know what kind of hydrogen bonds - strong or weak (here we follow the definitions given $\mathrm{in}^{40}$ ) ones-prevails in the form formulated for patient. It is clear a priori, the weaker are hydrogen bonds in solid substance the
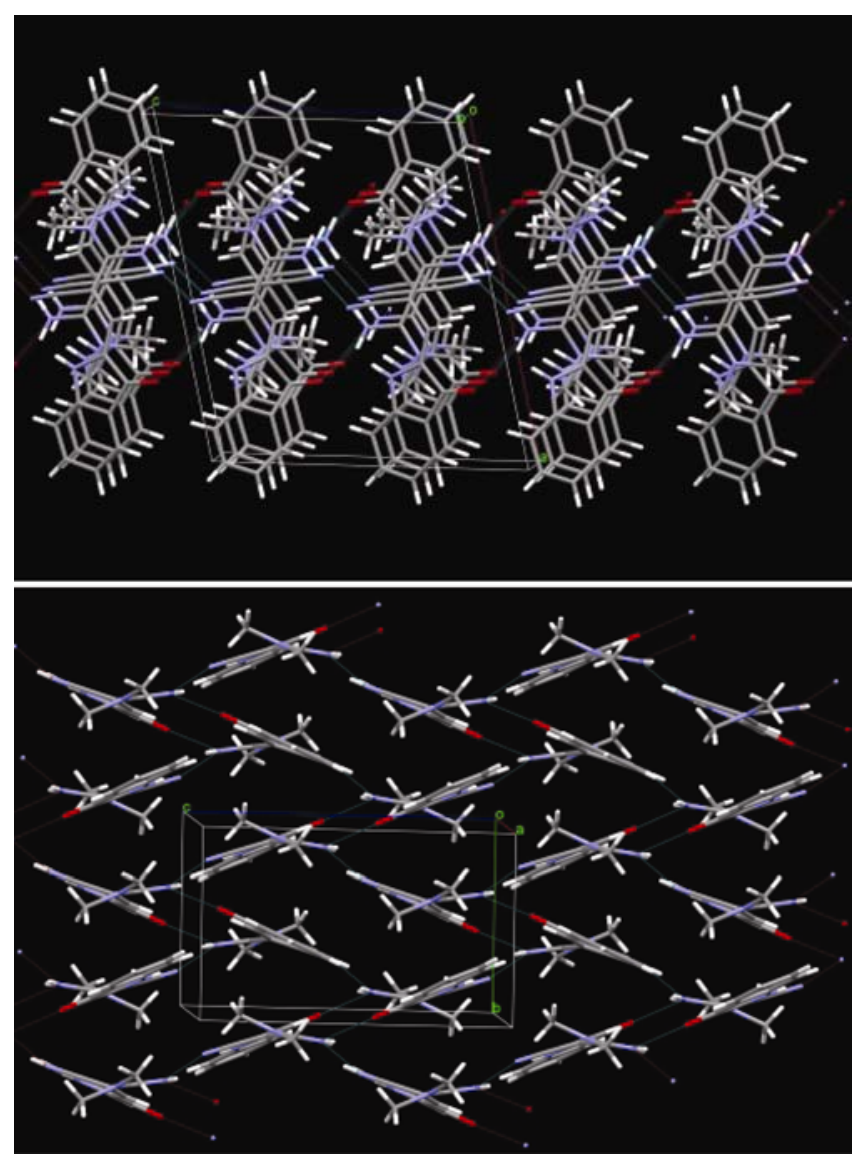

Figure 5. A portion of the crystal packing of 1 viewed in two orthogonal projections-approx. down the $b$ axis (top) and approx. down the $a$ axis (bottom). Dashed lines denote strong intermolecular hydrogen bonds. more soluble is it. The situations when drug molecules form dimers via strong hydrogen bonds, which block active centers of the molecules, have to be avoided. Because these inactive dimers are stable in solution, and their activation, i.e. separation into free molecules, requires an additional energy. The aforementioned arguments stimulate us to uncover the hydrogen-bonding pattern in any new substance exhibiting a potent pharmaceutical activity.

For 1-5, we discuss here only strong intermolecular $\mathrm{N}-\mathrm{H} \cdots \mathrm{O}$ and $\mathrm{N}-\mathrm{H} \cdots \mathrm{N}$ hydrogen bonds (table 3 ). In all molecules, there are obvious donors ( $\mathrm{N} 1$ and $\mathrm{N} 16)$ and acceptors (O10 and N14) of hydrogen bonds, and molecules 4 and 5 contains one more donor - atom N17, and all these donors and acceptors, except N1, are involved in formation of strong intermolecular hydrogen bonds. The involvement of atom $\mathrm{N} 1$ in intermolecular hydrogen bonding is sterically hindered by molecular conformations, where cyano group with the H-bond acceptor (N14) protect N1 allowing a formation of weak

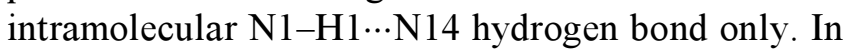
all compounds, except $\mathbf{3}$, strong intermolecular hydrogen bonds link molecules into two-dimensional layers with the hydrophobic surfaces-figure 5 shows such layer parallel to $b c$ plane in $\mathbf{1}$ in two orthogonal projections (the crystal packings of 2-5 are

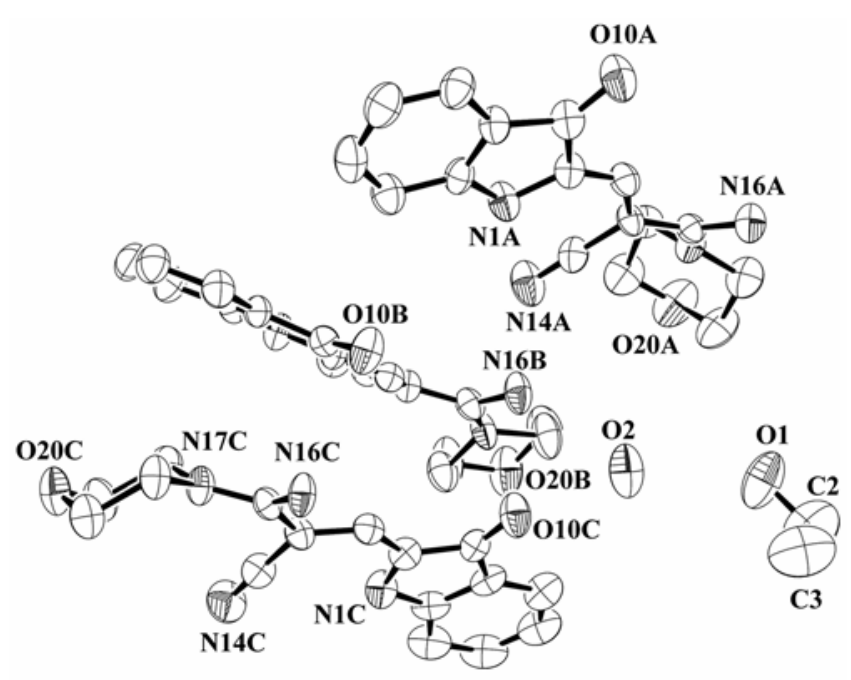

Figure 6. Three independent molecules - A, B and C, respectively, and two solvent molecules - water and ethanol, respectively - in asymmetric unit of 3a showing the atomic numbering and $50 \%$ probability displacement ellipsoids. Atomic numbering in molecules A, B and C corresponds to that in the molecule 3 in figure 3 with the added letters $\mathrm{A}, \mathrm{B}$ and $\mathrm{C}$, respectively. $\mathrm{H}$ atoms omitted for clarity. 
shown in supplementary figures S2-S5). In 3, strong intermolecular hydrogen bonds link molecules into columns propagated along axis $c$ (figure S3). Interestingly, atom N14 in $\mathbf{3}$ is not involved in strong hydrogen-bonding, so one can expect possible polymorphic modifications of this compound, where atom N14 will play a role of $\mathrm{H}$-bond acceptor, and the molecules will be linked into layers.

The asymmetric unit of $\mathbf{3 a}$ contains three molecules of 3 , one ethanol molecule and one water molecule (figure 6), which contain many centers of hydrogen bonds donors and acceptors. As a result, crystal packing of 3a exhibits an extensive threedimensional hydrogen-bonding network (table 4). This network helps to understand why multiple attempts required to synthesize unsolvated form of 3.

\section{Conclusion}

The crystal structures 1-5 routinely solved from powder diffraction data demonstrate that the wellaligned laboratory powder diffractometer can be used for structural characterization of new potent pharmaceuticals, validation of their molecular structures and hydrogen-bonding patterns.

\section{Supplementary information}

Crystallographic data for 1-5 and 3a have been deposited with the Cambridge Crystallographic Data Centre as supplementary publication Nos. CCDC 766130-766134 and 768553, respectively. Copies of data can be obtained free of charge on application to CCDC, 12 Union Road, Cambridge CB21EZ, UK (fax: (44)1223-336-033; e-mail: deposit@ccdc. cam.ac.uk). Supplementary figures S1-S5 can be found in website (www.ias.ac.in/chemsci).

\section{Acknowledgement}

Powder diffraction study of compounds 1-5 has been supported by the International Centre for Diffraction Data (ICDD; grant No. GiA 03-06).

\section{References}

1. David W I F, Shankland K, McCusker L B and Baerlocher Ch (eds) 2002 Structure determination from powder diffraction data (New York: Oxford University Press)
2. Baerlocher $\mathrm{Ch}$ and McCusker L B (eds) $2004 \mathrm{Z}$. Kristallogr. 219782

3. Harris K D M and Cheung E Y 2004 Chem. Soc. Rev. 33526

4. David W I F and Shankland K 2008 Acta Crystallogr. A A64 52

5. Chernyshev V V 2001 Izv. Acad. Nauk, Ser. Khim. 2171(in Russian) [Russ. Chem. Bull. 50 2273]

6. David W I F, Shankland K, van de Streek J, Pidcock E, Motherwell W D S and Cole J C $2006 \mathrm{~J}$. Appl. Crystallogr. 39910

7. Le Bail A 2001 Mater. Sci. Forum 378-381 65

8. Moliterni A G G, Altomare A, Caliandro R, Cuocci C, Giacovazzo C, Guagliardi A and Rizzi R 2002 Acta Crystallogr. A A58 (supplement) c266

9. Favre-Nicolin V and Cerný R 2002 J. Appl. Crystallogr. 35734

10. Rodriguez-Carvajal J 1990 Abstracts of the satellite meeting on powder diffraction of the $X V$ congress of the IUCr, Toulouse, France, p. 127

11. Larson A C and Von Dreele R B 1994 Report LAUR 86-748, Los Alamos National Laboratory, New Mexico, USA

12. Zlokazov V B and Chernyshev V V 1992 J. Appl. Crystallogr. 25447

13. Coelho A A 2007 TOPAS academic user manual. Coelho Software, Brisbane, Australia

14. Halasz I and Dinnebier R 2010 J. Pharm. Sci. 99871

15. Smrcok L, Cerný R, Boca M, Macková I and Kubíková B 2010 Acta Crystallogr. C C66 i16

16. Harper J K, Doebbler J A, Jacques E, Grant D M and Von Dreele R B $2010 \mathrm{~J}$. Am. Chem. Soc. (Article ASAP. DOI: $10.1021 /$ ja 907671 p)

17. Takeya S, Udachin K A, Moudrakovski I L, Susilo R and Ripmeester J A $2010 \mathrm{~J}$. Am. Chem. Soc. 132 524

18. Chernyshev V V, Kukushkin S Yu and Velikodny Yu A 2010 Acta Crystallogr. E E66 o613

19. McCusker L B, Baerlocher Ch, Wilson S T and Broach B R W 2009 J. Phys. Chem. C113 9838

20. Eiden F and Herdeis G 1978 Arch. Pharm. 311287

21. Ryabova S Yu, Alekseeva L M and Granik V G 1991 Khim. Geterotsikl. Soedin. 1191 (in Russian)

22. Ryabova S Yu, Trofimkin Yu I, Alekseeva L M, Kerbnikova I F, Shvarts G Ya and Granik V G 1995 Khim.-Pharm. Zh. 2922 (in Russian) [Pharm. Chem. J. 29 610]

23. Laikov D N 2004 Priroda Code, Version 5. Moscow State University, Moscow, Russia

24. Laikov D N 2005 Chem. Phys. Lett. 416116

25. Werner P-E, Eriksson L and Westdahl M $1985 \mathrm{~J}$. Appl. Crystallogr. 18367

26. Visser J W 1969 J. Appl. Crystallogr. 289

27. Zlokazov V B 1992 J. Appl. Crystallogr. 2569

28. Zlokazov V B 1995 Comput. Phys. Commun. 85 415

29. Pawley G S 1981 J. Appl. Crystallogr. 14357

30. Zhukov S G, Chernyshev V V, Babaev E V, Sonneveld E J and Schenk H 2001 Z. Kristallogr. 2165

31. Allen F H 2002 Acta Crystallogr. B B58 380

32. Toraya H 1986 J. Appl. Crystallogr. 19440 
33. Sheldrick G M 2008 Acta Crystallogr. B B64 112

34. de Wolff P M 1968 J. Appl. Crystallogr. 1108

35. Smith G S and Snyder R L 1979 J. Appl. Crystallogr. 1260

36. Young R A and Wiles D B 1982 J. Appl. Crystallogr. 15430

37. Ryabova S Yu, Rastorgueva N A, Sonneveld E J, Peschar R, Schenk H, Tafeenko V A, Aslanov L A and Chernyshev V V 2005 Acta Crystallogr. B B61 192

38. Panigrahi S K and Desiraju G R 2007 Proteins 67128

39. Panigrahi S K and Desiraju G R 2007 J. Biosci. 32 677

40. Desiraju G R and Steiner T 1999 The weak hydrogen bond in structural chemistry and biology (Oxford: Oxford University Press) 